\title{
A Reevaluation of Tree Model, Inflorescence Morphology, and Sex Ratio in Lychee (Litchi Chinensis Sonn.)
}

\author{
Hannes Robbertse \\ Department of Crop Production and Soil Science, University of Pretoria, Pretoria, 0002, South Africa
}

Jaco Fivaz

Institute For Tropical and Subtropical Crops, Private Bag X 11208, Nelspruit, 1200, South Africa

Chris Menzel

Maroochy Horticultural Research Station, Queensland Department of Primary Industries, P.O. Box 5083, Sunshine Coast Mail Centre, Nambour, Queensland, 4560, Australia

Additional index words. lychee, inflorescence, pleiothyrsoid, modular growth

\begin{abstract}
The architecture of the lychee tree and the structure of the inflorescence are described according to the terminology of Hallè et al. and Weberling. The lychee tree has rhythmic modular growth and the inflorescence is a heterocladic pleiothyrsoid. Additional paracladia may develop from a second serial bud below the first-order paracladia. Male and female flowers are borne at variable positions on the dichasia. The relation between the position and gender of the flowers on the partial inflorescences (dichasia) varied with cultivar and time.
\end{abstract}

Inflorescence terminology has, for a long time, been in an unsatisfactory state. Rickett (1944) stated that "names applied to inflorescences were confused from the beginning." It is, therefore, not surprising that descriptions of inflorescences in the applied fields of botany have not always kept pace with more recent terminologies. Weberling's (1992) book on morphology of flowers and inflorescences contributed greatly to a better understanding of the inflorescence structure, as well as terminology, and supplies clear descriptions of the different types. Most of Weberling's descriptions are, however, based on the inflorescences of annual herbaceous plants where the whole plant is usually hapaxanthic and the vegetative part is very often subordinate to the inflorescence. When applying these inflorescence types to woody plants, the tree architecture is involved and must be considered.

The way in which inflorescences are borne on a tree is closely related to the branching and growth pattern of the species involved. Tree models for the avocado and mango, based on the branching pattern and position of the inflorescence, were described by Hallè et al. (1978). Such a model has not yet been described for the lychee (Litchi chinensis Sonn.), an important crop of the subtropics.

It has become customary to describe the lychee inflorescence as a panicle (Banerji and Chaudhuri, 1944; Joubert, 1985; Menzel, 1983, 1984), although this does not fit Weberling's (1992) general description. According to Menzel (1984), and Menzel and Simpson (1992) and references therein, the flowers are, in order of appearance, functionally male, functionally female and functionally male, but no mention is made about relation between the position of the flowers on the inflorescence and their gender. Banarji and Chaudhuri (1944) mention that the flowers occur in cymes which are entirely male, entirely female, terminated by a male flower with lateral female flowers, terminated by a female flower with lateral male flowers, or terminated by a male flower with lateral flowers of different sexes. Mustard (1960) and Joubert (1985) also mention male, female, and functionally male flowers without relating sex to position.

In this paper, the architecture of the air-layered lychee tree is described and related to the position of the inflorescence. We reevaluate the structure of the inflorescence and provide information on the position of the flowers on the cymes and their sex. The terminology for the tree model was adopted from Hallè et al. (1978), and for the inflorescence from Weberling (1992).

Fig. 1. Diagrammatic presentation of the lychee tree model in different stages of development. (A) Second year of flowering, (B) third year of flowering, (C) fourth year of flowering. $\mathrm{Rm}=$ most recent module, $\mathrm{Ti}=$ module terminating in an inflorescence, $\mathrm{Mt}=$ main trunk.
Received for publication 30 Jan. 1995. Accepted for publication 18 May 1995. Contribution from the Dept. of Crop Production and Soil Science, Univ. of Pretoria, South Africa, part of J.F's MS thesis. We acknowledge the South African Litchi Growers Association for financial support and the Univ. of Pretoria and the Faculty of Agriculture at the Hebrew Univ. of Jerusalem for providing the infrastructure for this investigation. The cost of publishing this paper was defrayed in part by the payment of page charges. Under postal regulations, this paper therefore must be hereby marked advertisement solely to indicate this fact.
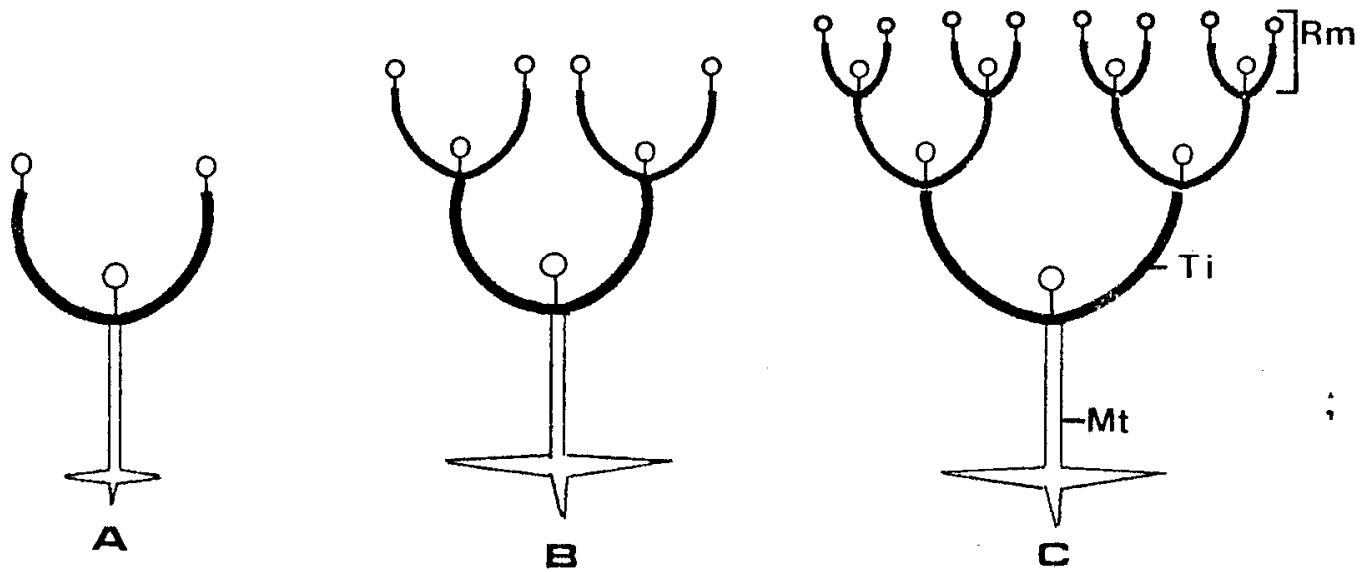


\section{Material and Methods}

Architectural studies were made by visual observations of five 12-year-old 'HLH Mauritius' and five 'Red McLean' trees growing at Nelspruit, South Africa $\left(25^{\circ} \mathrm{S}\right)$. Phenological studies of inflorescences were made by observing 7-year-old air-layered trees growing at Bet Dagan, Israel $\left(32^{\circ} \mathrm{N}\right)$. Three inflorescences per tree were used. From the cultivars 'HLH Mauritius' and 'Floridian', three different trees were used, while for the cultivars 'Bengal', 'Early Large Red', 'Garnet', 'Red McLean', 'Late Seedless' and 'Fay Zee Sui' two trees were used. Sixty-four cymes on four inflorescences on four 12-year-old 'HLH Mauritius' trees

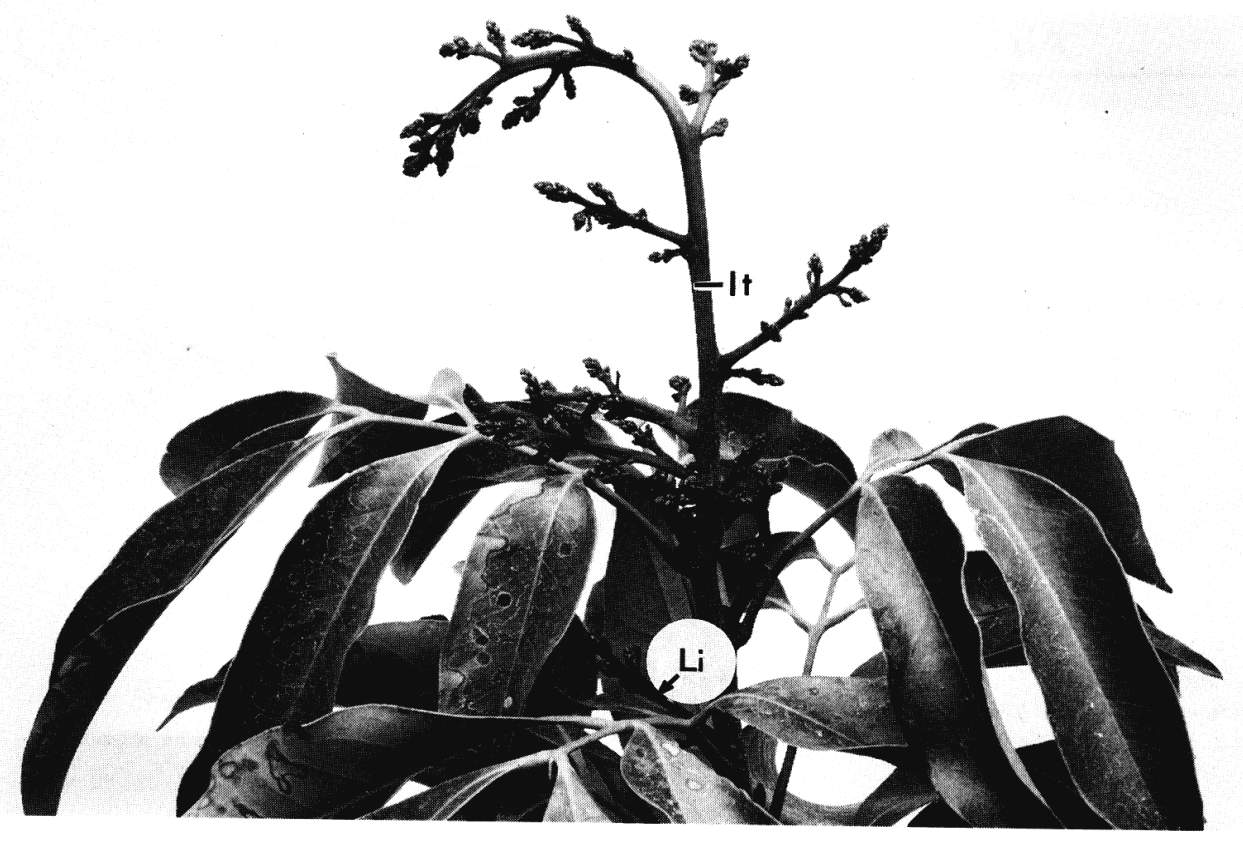

Fig. 2. Branch with terminal (Lt) and lateral inflorescences (Li).

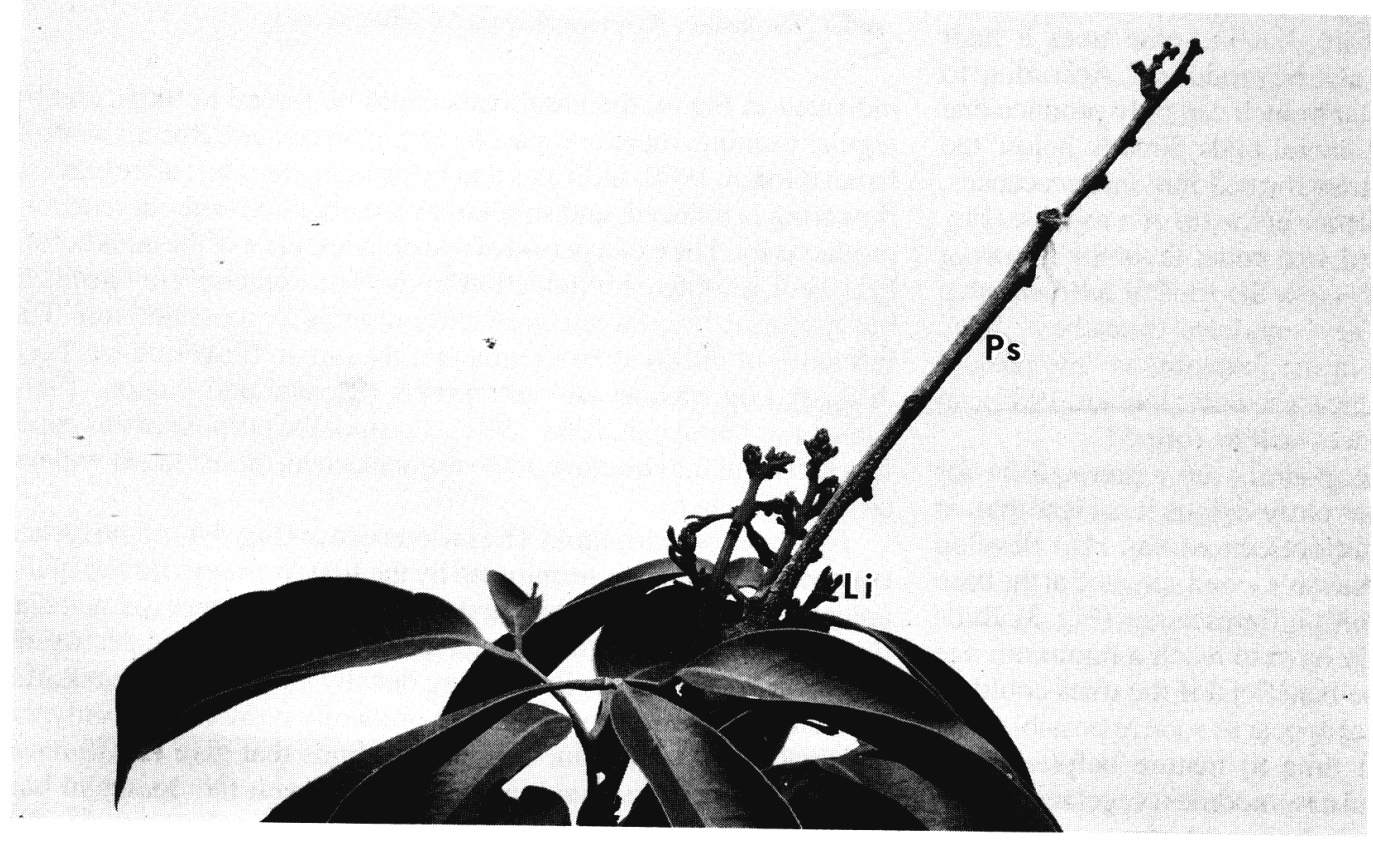

Fig. 3. Branch with inflorescence formed on previous season's (Ps) or new seasons growth (Li). growing at Nelspruit in South Africa were tagged just after bud break and the sex of the flowers observed weekly until the end of the flowering period. For all other phenological studies, observations were made daily over the entire flowering period (Israel: 22 Apr.-22 May 1993; South Africa 11 Sept.-7 Oct. 1993), which lasted for about 3 to 4 weeks. Young air layered trees in 20 liter containers were also used. These trees consisted of two batches. One batch of 20 'HLH Mauritius' ('Tai So') and 20 'Madras' ('Bengal') trees were obtained during August 1992 from a commercial nursery in Magoebaskloof $\left(23^{\circ} \mathrm{S}\right)$, South Africa. Trees with young inflorescences about 1 week after budbreak were transported to a greenhouse in Pretoria $\left(26^{\circ} \mathrm{S}\right)$. The second batch of 20 trees, from the same nursery were obtained during $\mathrm{Au}-$ gust 1993. Flower induction in the latter trees took place in the greenhouse in Pretoria. Five cymes per tree on inflorescences on these trees were also tagged.

\section{Results and Discussion}

Tree phenology. According to the terminology of Hallè and Martin (1968), growth of the lychee tree is rhythmic, meaning that "the shoots have a marked endogenous periodicity of extension." Periods of extension growth or flushes alternate with periods during which new leaf primordia are initiated from the apical dome, but without shoot elongation. Once a year, during cool weather, inflorescence primordia are initiated at the apical domes of the terminal buds. The same sequence of events was described by Banarji and Chaudhuri (1944). Inflorescences are, therefore, terminal and the branches on which they are produced are hapaxanthic (term used by Hallè et al., 1978), meaning that the "shoot apical meristem becomes wholly transformed into a flowering axis after a period of vegetative growth." All branches are morphologically equivalent and are borne on relay axes, repeating the construction of the parent axis. Growth of the tree is, therefore, modular (Fig. 1), representing Leeuwenberg's model (Hallè et al., 1978). In young, nonflowering trees branching occurs after spontaneous abortion of the terminal bud. But in flowering trees, branching usually occurs only after the terminal bud has been transformed into an inflorescence, and 'the fruit produced 


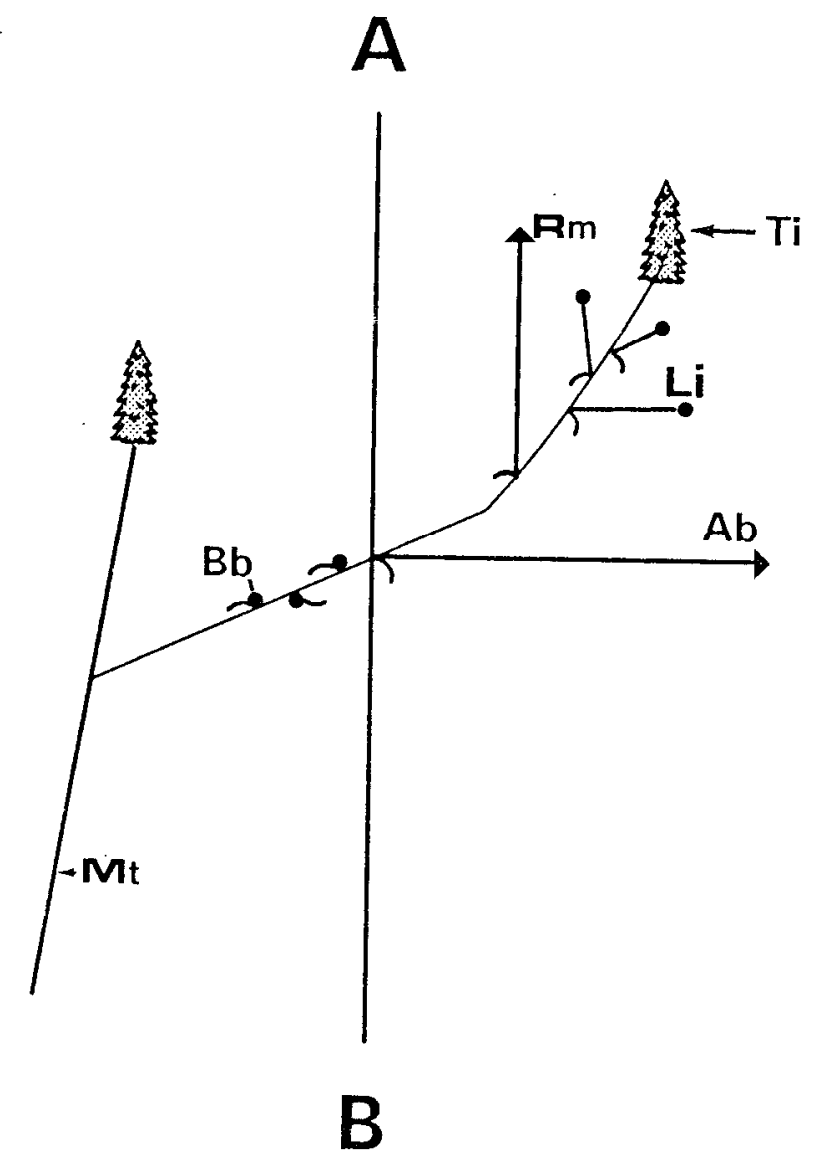

Fig. 4. Detail of the lychee branching system and suggested pruning (line $\mathrm{AB}$ ). $\mathrm{Ti}$ $=$ terminal inflorescence, $\mathrm{Ab}=$ subterminal branching as a result of pruning, $\mathrm{Bb}$ = basal dormant buds, $\mathrm{Li}=$ lateral inflorescence, $\mathrm{Rm}=$ most recent module (vegetative flush), $\mathrm{Mt}=$ main trunk.

have been clipped from the trees at harvest. Under adverse conditions, side shoots and inflorescences may also develop further down the branch and even on the trunk.

According to Menzel (1983), "panicles are normally produced terminally in clusters of 10 or more, but in some trees a high percentage of axillary panicles may also be produced". According to our view, the apical bud of a modular branch can only produce one inflorescence. One or more of the lateral buds directly below the apical bud may, however, also be transformed into inflorescences, resulting in more than one inflorescence at the tip of a module (Fig. 2). After the fruit has been harvested, and under favorable growing conditions, one or more of the buds below the zone of inflorescence production will flush to produce new modules (branches). Such modules represent what is known in the literature as "the present season's wood" (Menzel, 1983) or "new growth" (Joubert, 1985), on which the next season's inflorescences will be formed.

Some authors indicate that new modules are a prerequisite for flower production. According to our observations it is clear that, at least in the cultivar 'Mauritius', inflorescences can also develop directly from buds on the previous season's wood, situated at the base of the withered axes of the past season's inflorescences (Fig. 3). Buds on the new flush branches normally have to reach a minimum age before they can flower. It would be beneficial if the trees could be manipulated or pruned so that flushes appear as soon as possible after harvesting, giving buds sufficient time to mature before flower induction. Lateral inflorescences and new modules (vegetative flush) develop from subterminal buds, while the basal buds on the modules remain dormant (Fig. 4). By pruning the modules after harvesting, as

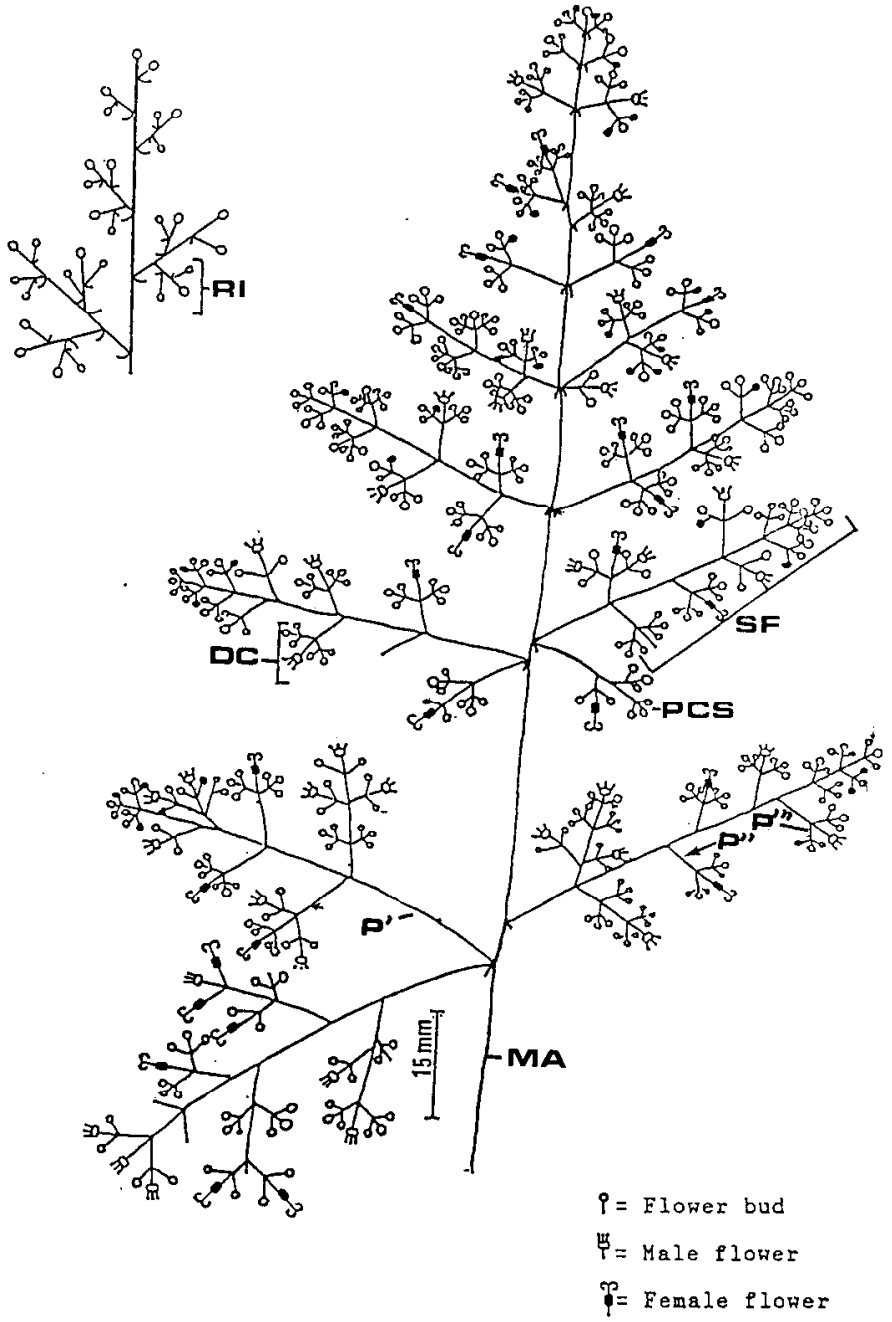

Fig. 5. Semi-diagrammatic presentation of lychee inflorescence (thyrsoid) (A) compared to a panicle (B). A Ma=main axis, Dc=dichasium (partial inflorescence), $\mathrm{Sf}=$ synflorescence from superposed bud, $\mathrm{PCS}=$ paracladium from subordinate bud, P'= first-order paracladium, P" = second-order paracladium, P"' = thirdorder paracladium. $\mathrm{Ri}=$ racemose partial inflorescence.

indicated in Fig. 4, the basal buds could be forced to flush, and by regular pruning, more compact trees can be created. Recent work in Israel (Goren, 1990) indicates that by pruning trees just after harvest, flowering is induced, and small trees are obtained without reducing productivity. The exact period of rest or quiescence of the buds before becoming receptive for induction has not been precisely determined, but appears to be between one to three months for most cultivars. The influence of different environmental factors on flowering has been discussed by Menzel and co-workers (Menzel and Paxton, 1986; Menzel and Simpson, 1988, 1991), but since the purpose of this paper was to look at the structure of the inflorescence, these factors will not be discussed here.

Inflorescence structure. The inflorescence (Fig. 5A) of the lychee consists of a main axis terminated by the first (primary) flower of the apical dichasium. One or two first-order lateral branches (paracladia) develop from the axils of minute, decussate, or distorted decussate, bracts on the main axis. Proceeding distally along the main axis, the first and higher-order branches are gradually reduced until only the terminal dichasia remain. The axillary buds that give rise to these lateral branches are found in series of two with the dominant bud superposed on the subordinate bud (term used by Bell, 1991). The occurrence of such serial buds has also been reported in inflores- 
cences of other species (Weberling, 1992). Sprouted subordinate buds which have formed subordinate paracladia (Fig. 5A) are constantly found in association with highly branched paraclades, and can drastically alter the appearance of the inflorescence and contribute to the uniqueness of the lychee thyrsoid. Similar to the main axis, the lateral branches are also terminated by dichasia. The dichasia or partial inflorescences (Fig. 6) are the basic flower bearing units of the inflorescence and may be borne on first-, second-, or third-order branches or paracladia. All flowers on the dichasia are subtended by minute bracteate prophylls.

The above conforms to Weberling's (1992) description of a pleiothyrsoid or determinate, compound thyrse. Different authors (Banarji and Chaudhuri, 1944; Joubert, 1985, 1986; Menzel, 1983;) described the lychee inflorescence as a panicle. Both the panicle and the thyrsoid are compound inflorescences, and in both the main and lateral axes are terminated by flowers (Fig. $5 \mathrm{~A}$ and B). Superficially, a panicle and thyrsoid look very similar, but differ in that the partial inflorescences or end branches are cymose in the thyrse but racemose in the panicle (Weberling, 1992). We suggest that the inflorescence of the lychee must be regarded as a thyrsoid, but due to its compound structure it is a pleiothyrsoid.
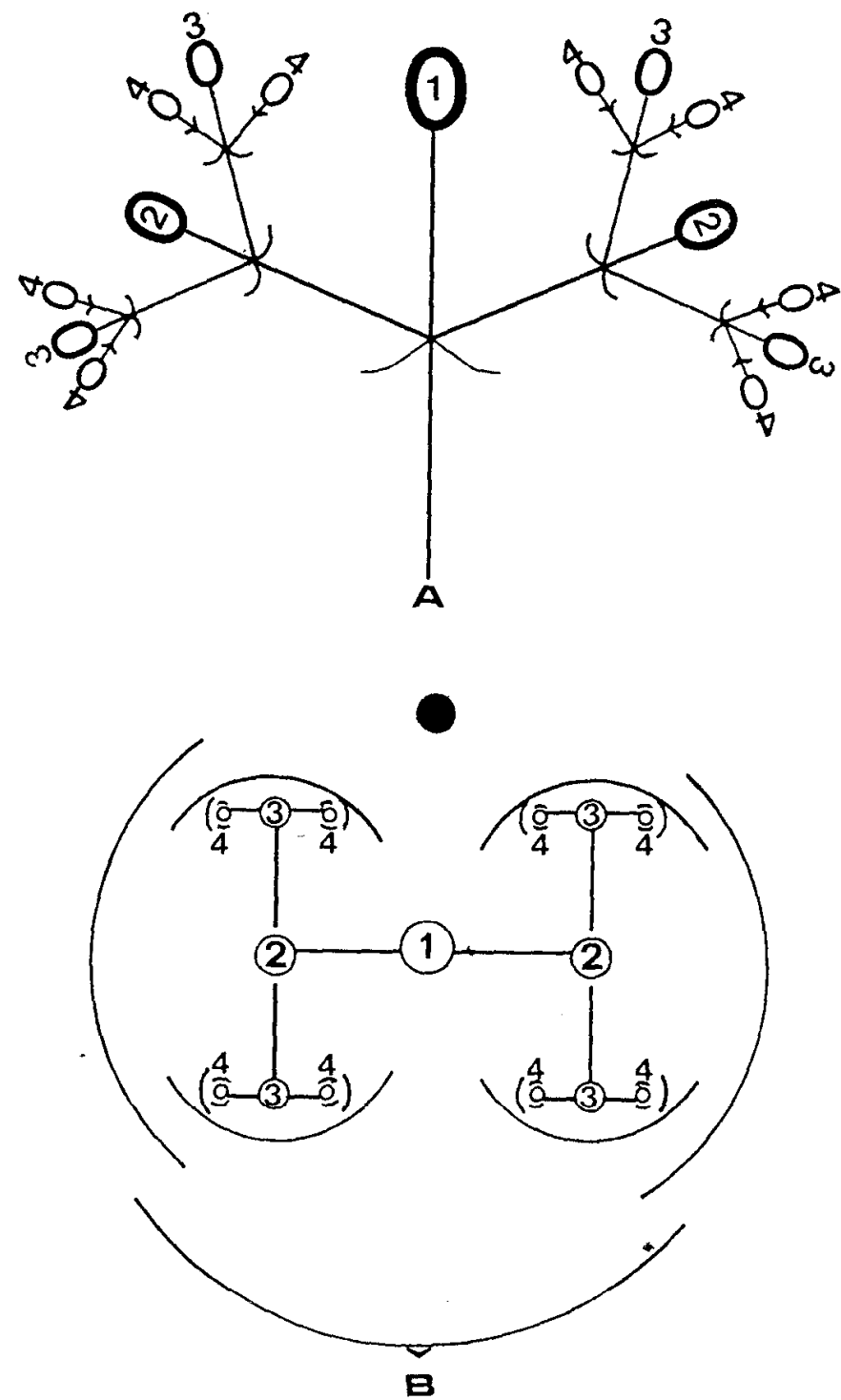

Fig. 6. Forms of lychee dichasia in lateral view (A) and top view (B) with numbers showing the sequence of flower anthesis.
Structurally, the lychee inflorescence conforms to the inflorescence of the mango, which was described by Barford (1988) as a conjunct, heterocladic pleiothyrsoid.

Flowers. The flowers are borne on the partial inflorescences or dichasia. Depending on the size of the inflorescence, the basal parts of the first-order paracladia can go through several branch orders before terminating in the dichasia. The basic plan of the lychee dichasium is given in Fig. 6. The first flowers to open on the inflorescence are the no. 1 flowers on proximally situated dichasia and in most cases represent first male phase (M,) flowers. The no. 2 flowers follow after a few days (usually female) and no. 3 flowers a few days later [usually second male phase (M,)]. Number 4 flowers usually remain in the undeveloped bud stage (Fig. 7A), but in more richly branched inflorescences these buds may also develop into flowers. Variation in the gender of the flowers in the different positions on the inflorescence can occur (Table 1; Figs. 6 and 7). The striated and dotted areas in Fig. 8 represent the number of dichasia of 'HLH Mauritius' trees with the sex of flowers related to different positions on the dichasia (Fig. 6). In the first inflorescence on a mature tree to start with anthesis, the no. 1 flowers are usually $M_{1}$ (Fig. 8A and Fig. 9), but they can be female on inflorescences developing later in the season or inflorescences of late flowering cultivars (Figs. $8 \mathrm{~B}$ and $\mathrm{C}$ and 9). Although female flowers in the no. 1 position were found in most of the late cultivars (Fig. 9), female flowers also occurred in the no. 2 position of the dichasia. Later in the flowering season, more dichasia were observed with female flowers in the no. 2 position, but were less than the number of dichasia with $\mathrm{M}_{2}$ flowers at this position (Fig. 8B). The $\mathrm{M}_{2}$ flowers are, however, not limited to position no. 2, but also occur at position no. 3 and position no. 4 in richly branched inflorescences (Fig. 8C and D).

Due to the construction of the dichasium, the number of open flowers on an inflorescence will, theoretically, be doubled every time as anthesis proceeds from the first generation of flowers (Fig. 6) to second and third flower generations, provided no buds abort. Inflorescences starting with the female phase (most of no. 1 flowers female), followed directly by the second male phase would, theoretically, have only half the number of female flowers available for fertilization compared to inflorescences starting in the male phase (most of no. 1 flowers male and no. 2 flowers female) (Table 1). In practice, the gender sequence is not followed strictly, as can be seen in Fig. 4 and Table 1. If the no. 1 and no. 2 flowers are female, followed by the second male phase in the no. 3 flower position, as in the "atypical" situation, the sex ratio between the female to male flowers will be 3:4 compared to the "typical" condition with $\mathrm{M}_{1}$ flowers in the no. 1 position, female flowers in the no. 2 position and $\mathrm{M}_{2}$ flowers at position no. 3 , where the sex ratio is 2:5. The "atypical" condition was observed in the small air-layered trees grown in the greenhouse at the Univ. of Pretoria, young trees in orchards in Israel, and at Nelspruit, and some late flowering mature trees. According to M. Goren (personal communication, 1993), this is well recorded among young trees, and has been observed in many cultivars.

According to Stem (1993), the pollen of the first male flowers are less viable than pollen from the second 'male flowers, and it would therefore be expected that trees with female flowers at the no. 1 and no. 2 positions and $M_{2}$ flowers at the no. 3 and no. 4 positions on the dichasia would set more fruit in a normal season. However, the no. 4 flowers were only found in late flowering and richly branched inflorescences. The ideal situation would be to manipulate trees to produce female flowers at the no. 1 and no. 2 positions and male 2 flowers at the no. 3 and no. 4 positions (usually $\mathrm{M}_{2}$ flowers) either by pruning or by careful site selection. 

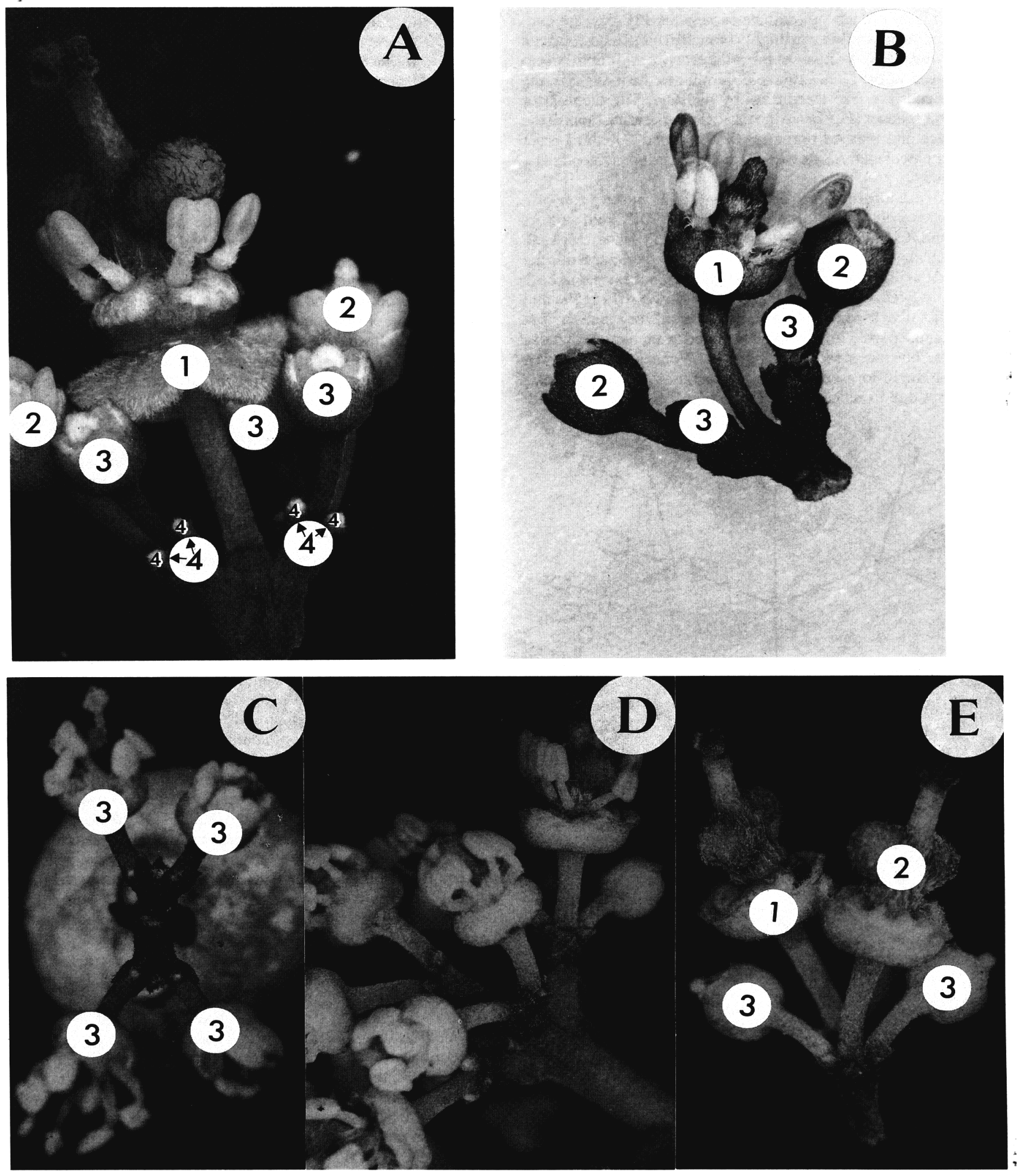

Fig. 7. Photographs of different dichasia showing different stages of development. Numbers represent the position of the flowers on the dichasium according to Fig. 5 . (A) 1,2 = Functionally female, 3 = functionally $\mathbf{M}_{2}, 4=$ undeveloped bud. (B) $1=$ Functionally $\mathbf{M}_{1}, 2=$ functionally female, $3=$ flower bud. (C) $1,2=$ Flowers aborted 3 = functionally $\mathbf{M}_{2}$. (D) Highly branched dichasmm. (E) 1,2,3 = Functionally female. 
Table 1. Observations regarding gender, position and sex ratio of flowers on dichasia of 'HLH Mauritius' trees in Nelspruit.

\begin{tabular}{lccccc}
\hline $\begin{array}{l}\text { Dichasia } \\
\text { observed }\end{array}$ & \multicolumn{5}{c}{$\begin{array}{c}\text { Flower position on dichasium } \\
\text { and sex of flower }\end{array}$} \\
\hline (no.) & 1 & 2 & 3 & 4 & M $_{1}:$ F $: \mathbf{M}_{2}$ \\
\hline 2 & Male 1 & Female & Female & Male 2 & $1: 6: 8$ \\
12 & Male 1 & Female & Male 2 & --- & $1: 2: 4$ \\
1 & Male 1 & Female & Male 2 & Male 2 & $1: 2: 12$ \\
15 & Female & Female & Male 2 & --- & $0: 3: 4$ \\
15 & Female & Male 2 & Male 2 & --- & $0: 1: 6$ \\
12 & Female & Male 2 & --- & -- & $0: 1: 2$ \\
2 & Female & Female & Female & Male 2 & $0: 7: 8$ \\
1 & Female & Female & --- & --- & $0: 3: 0$ \\
1 & Male 2 & Male 2 & --- & -- & $0: 0: 3$ \\
\hline
\end{tabular}

${ }^{\overline{2}} \mathrm{~F}=$ female, $\mathrm{M}^{1}=$ first male, $\mathbf{M}^{2}=$ second male

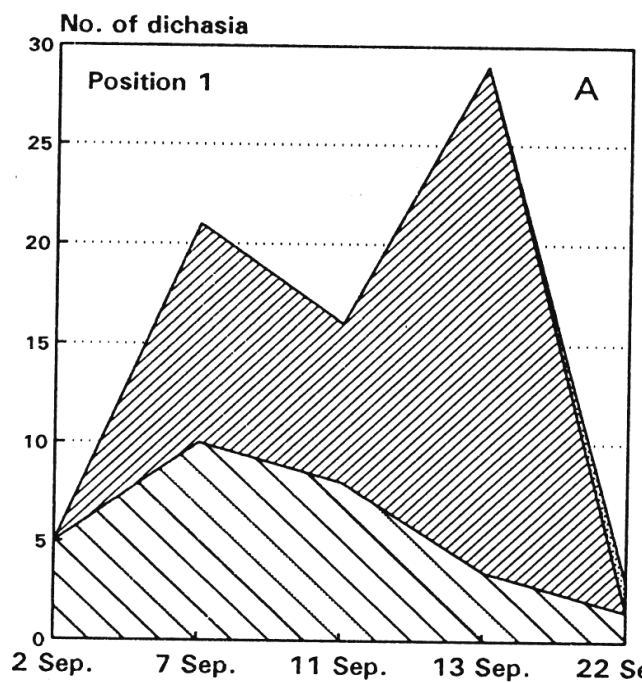

This will not only induce richly branched inflorescences but will also enable female flowers to be pollinated with the more viable pollen of the $\mathrm{M}_{2}$ flowers.

As previously stated, the existing descriptions of lychee inflorescences are rather vague, especially when it comes to the relation between the flower gender and position on the inflorescence (Joubert, 1985; Menzel, 1984). We hope that our interpretation of the lychee inflorescence will contribute to a better understanding of flowering in this species, and emphasize the importance of having a reliable model of flower development when studying factors affecting fruit set. It is clear that the sex ratio of the flowers on the same inflorescence is to a great extent determined by the sex of the no. 1 flowers on the dichasia. Due to the existing variation in this regard, it may be possible to manipulate the sex of the no. 1 flowers. It is also possible that the position of the female flower on the dichasium could play a role in fruit abscission.

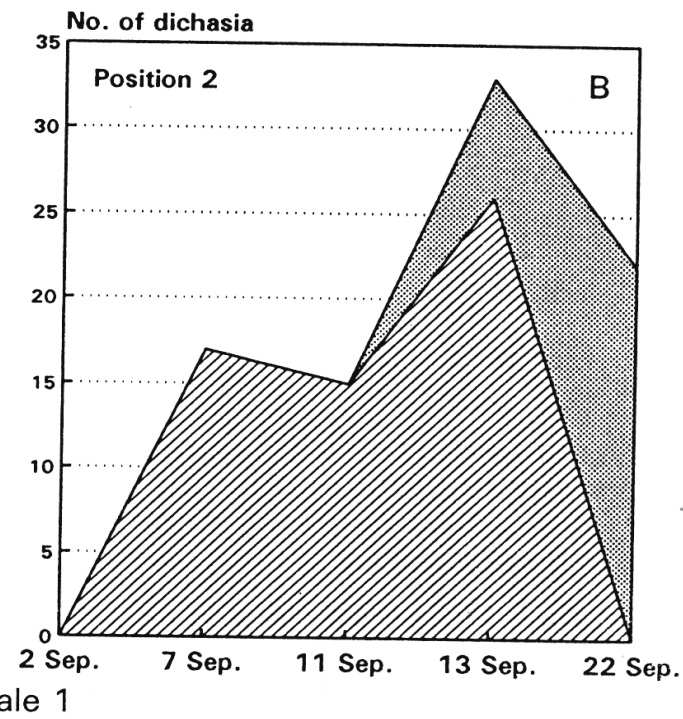

\section{Female}

Male 2
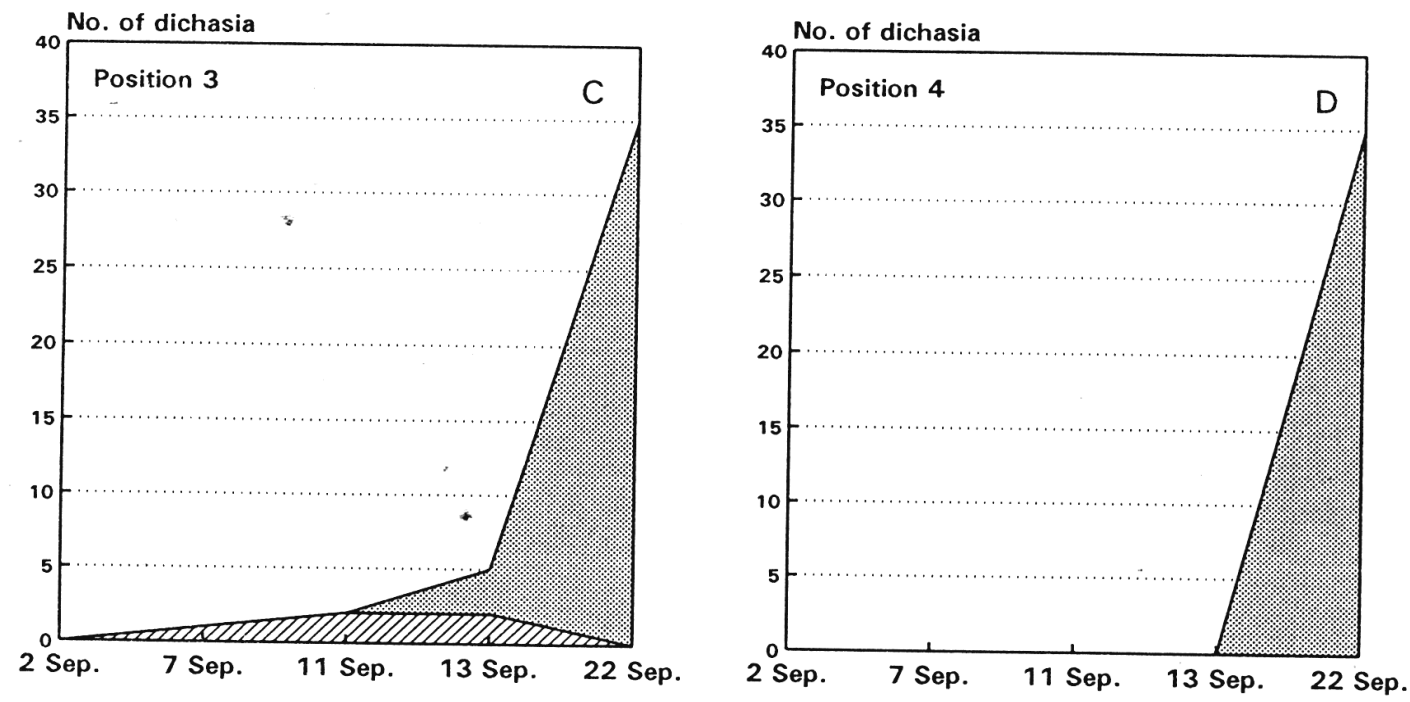

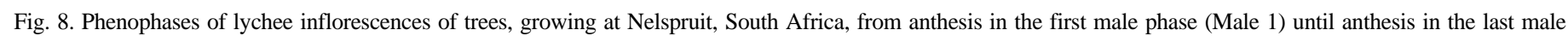
phase (Male 2). (A-D). Positions 14 on dichasia according to Fig. 6. 


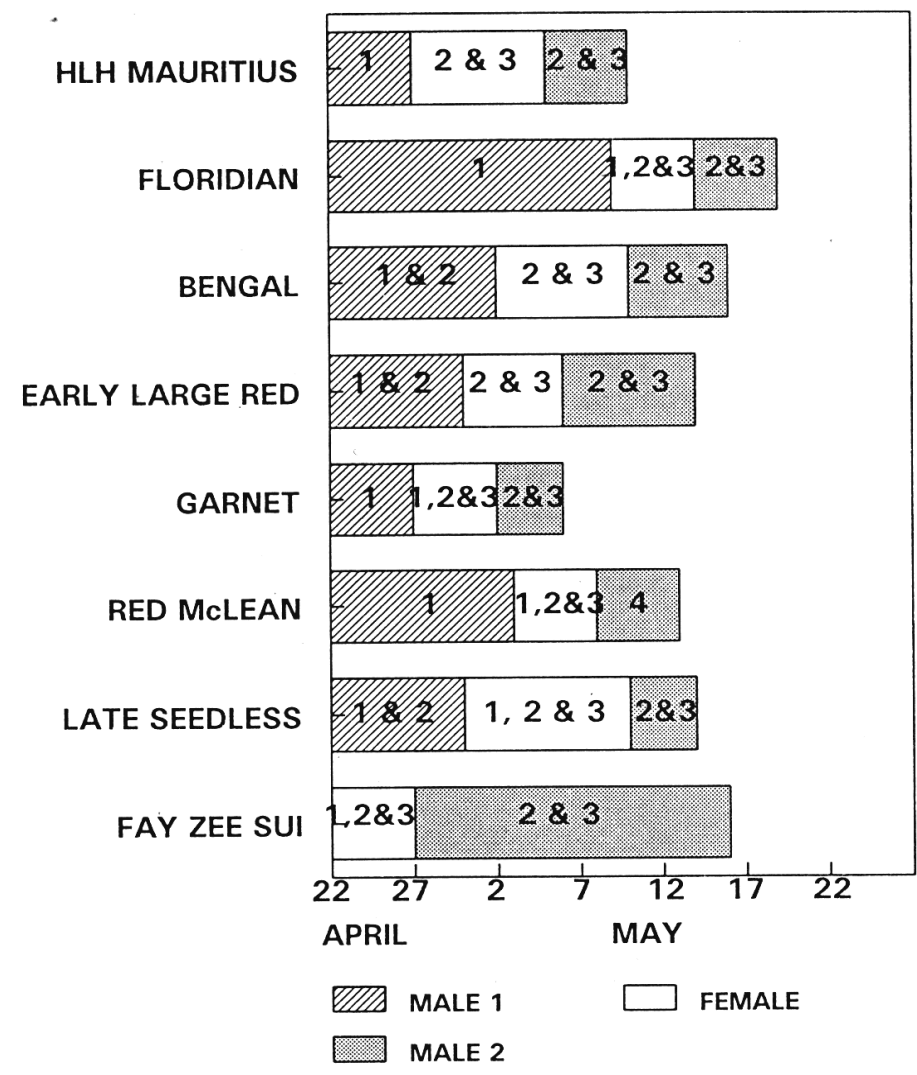

Fig. 9. Phenograms of eight lychee cultivars grown at Bet Dagan, Israel. Positions 14 on dichasia according to Fig. 6.

\section{Literature Cited}

Banerji,, I. and K.I. Chaudhuri. 1944. Contribution to the life history of Litchi chinensis Sonn. Proc. Indian Acad. Sci. 11:19-27.
Barford, A. 1988. Inflorescence morphology of some South American Anacardiaceae and possible phylogenetic trends. Nord. J. Bot. 8:3-11.

Bell, A.D. 1991. Plant Form: An illustrated guide to flowering plant morphology. Oxford Univ. Press. Oxford.

Goren, M. 1990. High density litchi orchards by reducing tree height. Alon Hanotea 44:699-704. (In Hebrew).

Hallè, F. and R. Martin. 1968. Etude de la croissance rythmique chez 1'Hévéa (Hevea brasiliensis Müll. Arg. Euphorbiacées-Crotonoidées). Adansonia 8:475-503.

Hallè, F., R.A.A. Oldeman, and P.B. Tomlinson. 1978. Tropical trees and forests. An architectural analysis. Springer-Verlag, New York.

Joubert, A.J. 1985. Litchi., p. 204-210. In: A.H. Halevy (ed.). Handbookof flowering, Vol.5 CRC Press, Boca Raton. Fla.

Joubert, A.J. 1986. Litchi, p. 233-246. In: S.P. Monselise (ed.). Handbook of fruit and seed development. CRC Press, Boca Raton, Fla.

Menzel, C.M. 1983. The control of floral initiation in lychee: A review. Sci. Hort. 21:201-215.

Menzel, C.M. 1984. The pattern and control of reproductive development in lychee: A review. Sci. Hort. 22:333-345.

Menzel, C.M. and B.F. Paxton. 1986. The effect of cincturing at different stages of vegetative flush maturity on the flowering of litchi (Litchi chinensis Sonn.). J. Hort. Sci. 61:135-139.

Menzel, C.M. and D.R Simpson. 1988. Effect of temperature on growth and flowering of litchi (Litchi chinensis Sonn.) cultivars. J. Hort. Sci. 63:349-360.

Menzel, C.M. and D.R. Simpson. 1991. Effects of temperature and leaf water stress on panicle development of litchi (Litchi chinensis Sonn.) J. Hort. Sci. 66:335-344.

Menzel, C.M. and D.R. Simpson. 1992. Flowering and fruit set in lychee (Litchi chinensis Sonn.) in subtropical Queensland. Austal. J. Expt. Agr. 32: 105-111.

Mustard M.J. 1960. Megagametophytes of the lychee (Litchi chinensis Sonn.). Proc. Amer. Soc. Hort. Sci. 75:292-304.

Rickett, H.W. 1944. The classification of inflorescences. Bot. Rev. 10: 187231.

Stem, R.A. 1993. Elucidation of the factors affecting litchi productivity in Israel, and the development of methods to improve its yield. Ph.D. thesis, Hebrew Univ. of Jerusalem, Rehovot.

Weberling, F. 1992. Morphology of flowering plants. Cambridge Univ. Press, Cambridge. 